Original Research Paper

\title{
Prediction of Body Weight of Yearling Boer Goats from Morphometric Traits using Classification and Regression Tree
}

\author{
Madumetja Cyril Mathapo and Thobela Louis Tyasi \\ School of Agricultural and Environmental Sciences, Department of Agricultural Economics and Animal Production, \\ University of Limpopo, Private Bag X1106, Sovenga 0727, Limpopo, South Africa
}

\author{
Article history \\ Received: 28-01-2021 \\ Revised: 24-03-2021 \\ Accepted: 29-03-2021 \\ Corresponding Author: \\ Thobela Louis Tyasi \\ School of Agricultural and \\ Environmental Sciences, \\ Department of Agricultural \\ Economics and Animal \\ Production, University of \\ Limpopo, Private Bag X1106, \\ Sovenga 0727, Limpopo, South \\ Africa \\ Email: louis.tyasi@ul.ac.za
}

\begin{abstract}
Classification and Regression Tree (CART) is a predictive algorithm method used to explains how the dependent variable can be predicted using independent variables (numerical and characters). The study was conducted to investigate the relationship between body weight and morphometric traits (Body Length (BL), Heart Girth (HG), Rump Height (RH), Rump Width (RW), Ear Length (EL), Cannon Circumference (CC) and Head Width (HW)) and to estimate body weight from morphometric traits in yearling Boer goats. In addition, age and sex were also considered. A total of seventy-one (71) yearling Boer goats (female $=57$ and male $=14$ ) between the age of one year and two years old were used. Pearson correlation and CART were used for data analysis. Correlation results indicated that $\mathrm{BW}$ of female goats was highly positive significant at $(\mathrm{P}<0.01)$ with $\mathrm{HG}(\mathrm{r}=0.828)$ and $\mathrm{BL}(\mathrm{r}=0.621)$ and consistently positively correlated at $(\mathrm{P}<0.05)$ with $\mathrm{RH}(\mathrm{r}=0.558)$ and HW $(r=0.512)$, while BW of male goats was highly positive significant at $(\mathrm{P}<0.01)$ with BL $(\mathrm{r}=0.727), \mathrm{CC}(\mathrm{r}=0.642), \mathrm{HG}(\mathrm{r}=0.564), \mathrm{RW}(\mathrm{r}=$ $0.361)$ and EL $(r=0.340)$ and consistently positively significant at $(\mathrm{P}<0.05)$ correlated with $\mathrm{RH}(\mathrm{r}=0.317)$. CART findings showed that sex played a crucial role on body weight of yearling Boer goats. Correlation results suggest that morphometric traits of yearling Boer goats might be used to improve body weight. CART model developed in this study could be used by breeders to advice resource-limited Boer goats' farmers which morphometric traits they can use to select their animals in order to improve their herd. However, further studies need to be done to validate the use of CART in prediction of body weight from morphometric traits of yearling Boer goats using large sample size, different area or other goat breeds.
\end{abstract}

Keywords: Body Length, Ear Length, Heart Girth, Head Width, Rump Width, Rump Height

\section{Introduction}

Boer goat are breeds which were grown/bred in South Africa in the early $1900 \mathrm{~s}$ for meat production (Casey and Niekerk, 1989). According to (Lu, 2002) Boer goats obtained worldwide recognition for their magnificent body conformation, fast growing rate and good carcass quality. Boer goats are hardy breeds which can survive in different conditions. Body weight of animals is very much important as it helps farmers to manage their animals such as selecting males and females for breeding, adjusting feed supply and dosage. It can also help them to set price for their live animals when selling (Tariq et al., 2012; Norris et al., 2015). However, smallholder farmers in remote areas do not have access to weighing scale due to its prohibited (Olatunji-Akioye and Adeyemo, 2009). Classification and regression tree have been used for estimation of body weight using morphological traits in Balochi sheep (Huma and Iqbal, 2019) and in Beetal goats of Pakistan (Eyduran et al., 2017). Classification and regression trees are a modern technique used for purpose of prior selection of the traits which have a statistical 
influence on the dependent variable (Piwczyński, 2009). However, there is a scarce information on prediction of body weight from morphometric traits of yearling Boer goats using classification and regression tree. The objectives of the current study were to (1) determine the relationship between body weight and morphometric traits (body length, heart girth, rump width, ear length, cannon circumference, head width and rump length) of yearling Boer goats using Pearson correlation and (2) to develop a model to predict body weight from morphometric traits using classification and regression tree. This study will help resource-limited farmers to know the relationship between body weight and morphometric traits of Boer goats and which traits they can use to improve and estimate body weight, so that they can practice animal management such as selecting animals for breeding, providing required feeds, vaccination dosage and also to be able to set price for their goats when selling.

\section{Materials and Methods}

\section{Study Site}

The study was conducted at Pieter Smith Boer goat farm located in Allays Limpopo of South Africa. A total of 71 yearling Boer goats (14 which are males and 57 females) aged between one and two years old were used. All goats were allowed to graze freely in the camps and come back to the kraal in the afternoon, where they were provided with water and feeds. Dipping is also practiced regularly.

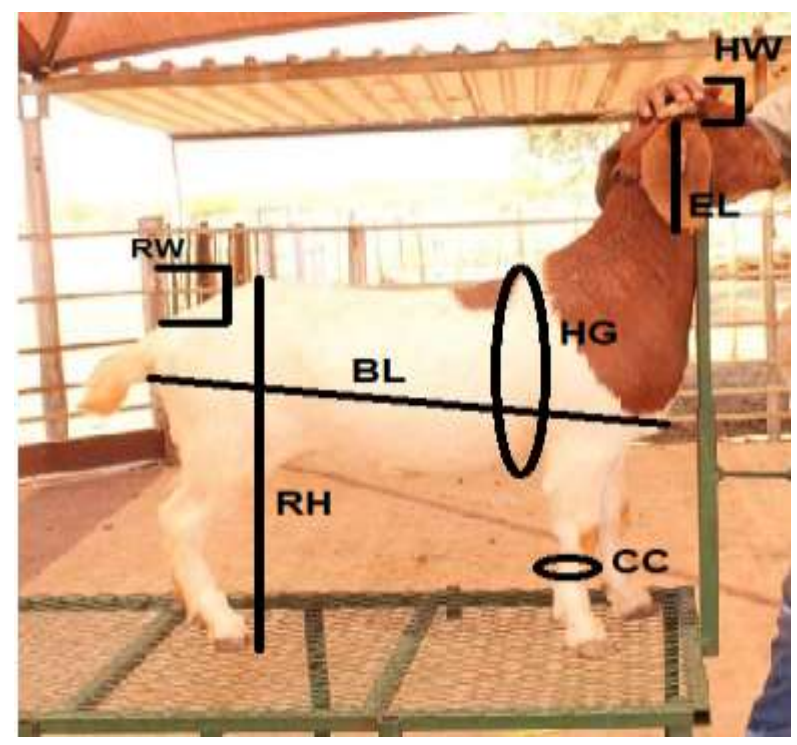

Fig. 1: Boer goat displaying morphometric traits measured in the study. HW: Head Width, EL: Ear Length, HG: Heart Girth, CC: Cannon Circumferences, BL: Body Length, RH: Rump Height, RW: Rump Width

\section{Data Collection}

Morphometric traits were measured using tailor measuring tape and a wood ruler calibrated in centimeters $(\mathrm{cm})$ as shown in Fig. 1 while body weight was measured using a weighing scale calibrated in kilograms $(\mathrm{kg})$ that weighs up to $300 \mathrm{~kg}$ with accuracy of $100 \mathrm{gm}$.

All the measurements were taken as previously prescribed by (Lukuyu et al., 2016). Briefly, Body Length (BL) distance from the occipital protuberance to the base of the tail), Heart Girth (HG) circumference of the chest, Rump Height (RH) distance from the ground to the rump, Ear Length (EL) space from the position of attachment to the tip of the ear, Head Width (HW) measured as the space between the edges of the head, Cannon Circumference (CC) measured as the smallest circumference of the foreleg, (RW) measured as the position between two tuber coxae. Only one person was appointed to take the measurements to avoid errors.

\section{Statistical Analysis}

Data analysis was performed using Statistical Package for Social Sciences software IBM SPSS, 2019 version 26. Mean procedure was used for descriptive statistics. Correlation was used to determine the association between body weight and morphometric traits. CART was used to establish a model to predict body weight from morphometric traits.

\section{Results}

Descriptive statistics of body weight and morphometric traits (Body length, Heart girth, Rump height, Rump width, Ear length, cannon circumference and Head width) for this study are shown in Table 1. The summary indicated that body weight means numerical values of bucks $(100.79 \mathrm{~kg})$ was higher than of does $(46.51 \mathrm{~kg})$. The summary of morphometric traits indicated that bucks had higher mean numerical values in all traits $(\mathrm{BL}=96.86 \mathrm{~cm}, \mathrm{HG}=103.64 \mathrm{~cm}, \mathrm{RW}=26.21 \mathrm{~cm}, \mathrm{EL}=$ $22.89 \mathrm{~cm}, \mathrm{CC}=15.00 \mathrm{~cm}, \mathrm{RH}=76.93 \mathrm{~cm}$ ) as compared to those of does. It also indicated on the top that bucks were $(n=14)$ in numbers less than the does $(n=57)$. The summary of measured traits showed that bucks had higher means values in all traits. However, our data was different from the findings of (Tyasi et al., 2020) in South African non-descript indigenous goats. This might be caused by breed variation and environment.

Phenotypic correlations: Pearson's was used to achieve first objective: The relationship between body weight and morphometric traits in male (bucks) and female (does) of yearling Boer goats in Table 2. The correlation coefficients above diagonal show correlation results of does and below diagonal are of bucks. Our Findings indicated that body weight of does had a highly positive significant correlation with body length $(\mathrm{r}=$ 
$\left.0.727^{* *}\right)$, cannon circumference $\left(r=0.642^{* *}\right)$, heart girth $\left(\mathrm{r}=0.564^{* *}\right)$, rump width $\left(\mathrm{r}=0.361^{* *}\right)$ and positive correlated to rump height $\left(\mathrm{r}=0.317^{*}\right)$ and head width $\left(\mathrm{r}=0.223^{*}\right)$ respectively. Head width $(\mathrm{HW})$ was found to be not significant with other morphometric traits $\left(\mathrm{BL}, \mathrm{r}=-0.020^{\mathrm{ns}}\right.$ : HG, $\mathrm{r}=0.177^{\mathrm{ns}}: \mathrm{RW}, \mathrm{r}=0.019^{\mathrm{ns}}: \mathrm{EL}$, $\mathrm{r}=-0.177^{\mathrm{ns}}$ and $\left.\mathrm{CC}, \mathrm{r}=-0.177^{\mathrm{ns}}\right)$, but significant with body weight and rump height was also seen to be not significant with $\left(\mathrm{BL}, \mathrm{r}=-0.048^{\mathrm{ns}}\right.$ : $\mathrm{HG}, \mathrm{r}=0.207^{\mathrm{ns}}$ : EL, $\mathrm{r}=0.008^{\mathrm{ns}}: \mathrm{CC}, \mathrm{r}=0.191^{\mathrm{ns}}$ ) while significant with (BW, $\mathrm{r}=0.317^{*}$ and $\mathrm{HW}, \mathrm{r}=0.292^{*}$ ) respectively. However, correlation coefficients of bucks below diagonal indicated that $\mathrm{BW}$ had a highly positive significant correlation with $\left(\mathrm{HG}, \mathrm{r}=0.828^{* *}\right.$ and $\mathrm{BL}, \mathrm{r}$ $\left.=0.621^{* *}\right)$ and positively significant correlation with $\left(\mathrm{RH}, \mathrm{r}=0.558^{*}\right.$ and $\left.\mathrm{HW}, \mathrm{r}=0.512^{*}\right)$ respectively while RW $\left(\mathrm{r}=0.311^{\mathrm{ns}}\right), \mathrm{EL}\left(\mathrm{r}=-0.251^{\mathrm{ns}}\right)$ and $\mathrm{CC}\left(\mathrm{r}=0.358^{\mathrm{ns}}\right)$ were not significant to $\mathrm{BW}$. The results also revealed some morphometric traits were not significant amongst each other. EL was not significant to BL $\left(r=0.174^{\mathrm{ns}}\right)$, HG $\left(r=-0.158^{n s}\right)$ and RW $\left(r=0.043^{n s}\right)$, CC was not significant to RW $\left(r=0.444^{\text {ns }}\right)$, HW was not significant to $\mathrm{HG}\left(\mathrm{r}=0.389^{\mathrm{ns}}\right)$, EL $\left(\mathrm{r}=0.057^{\mathrm{ns}}\right)$ and $\mathrm{CC}\left(\mathrm{r}=0.276^{\mathrm{ns}}\right)$, RH was also found not being significant with RW ( $\mathrm{r}=$ $\left.0.394^{\mathrm{ns}}\right)$, EL $\left(\mathrm{r}=0.084^{\mathrm{ns}}\right)$ and $\mathrm{CC}\left(\mathrm{r}=0.414^{\mathrm{ns}}\right)$.

Classification and regression tree: The regression tree model constructed by CART algorithm in the current study revealed that sex was the premier influencer of body weight of yearling Boer goats (Fig.
2 ). The other traits which played a crucial role on body weight were, heart girth and age. The first node, which is node 0 predicted an overall body weight of $57.21 \mathrm{~kg}$. Node 0 was subdivided based on sex into node 1 female ( $\mathrm{n}=57$, predicted weight $46.51 \mathrm{~kg}$ ) and node 2 male ( $\mathrm{n}$ $=14$, predicted weight $=100.79 \mathrm{~kg}$ ). Node 1 was split into node 3 and node 4 based on heart girth. Yearling Boer goats with Heart girth less or equals to $87.50 \mathrm{~cm}$ $(n=45)$ and those with heart girth greater than 87.50 $\mathrm{cm}(\mathrm{n}=12)$. These had predicted body weights of 42.52 $\mathrm{kg}$ and $61.41 \mathrm{~kg}$, respectively. Node 3 was also split into node 5 and node 6 based on age. Node 5 Yearling Boer goats with thirteen, fourteen and eighteen months were $(n=10)$ with predicted body weight of $45.37 \mathrm{~kg}$ while node 6 showed yearling Boer goats with one year were $(n=14)$ with predicted body weight of $36.24 \mathrm{~kg}$. Nodes 2,4,5 and 6 where terminal nodes as no partition was observed for providing homogeneousness in these nodes. In all the terminal nodes, node 2 was found to be the best node as it recorded the highest predicted mean $(100.76 \mathrm{~kg})$ as compared to node $4(61.42 \mathrm{~kg})$, node $5(45.37 \mathrm{~kg})$ and node $6(36.24 \mathrm{~kg})$. This model showed that node 6 had the lowest variance $\left[(3.246)^{2}=\right.$ $10.54]$ and the variance of the root node or dependent variable (body weight) was $S^{2} y=(24.149)^{2}=583.174$. The unexplained variation in the body weight was $S^{2} \mathrm{e}$ $=$ risk value $\div S^{2} y=49.534 \div 583.174=0.085$ and the variation in the model was explained as $\mathrm{S}^{2} \mathrm{y}=1-\mathrm{S}^{2} \mathrm{e}=$ $1-0.085=0.915$, respectively.

Table 1: descriptive statistics for BW and morphometric traits of yearling Boer goats

\begin{tabular}{|c|c|c|c|c|}
\hline \multirow[b]{2}{*}{ Traits } & \multicolumn{2}{|c|}{$\operatorname{MALE}(\mathrm{n}=14)$} & \multicolumn{2}{|c|}{ FEMALE $(n=57)$} \\
\hline & Mean & $\mathrm{CV} \%$ & Mean & $\mathrm{CV} \%$ \\
\hline$\overline{\mathrm{BW}}$ & $100.79 \pm 3.69$ & 13.80 & $46.51 \pm 1.28$ & 9.66 \\
\hline BL & $96.86 \pm 1.90$ & 7.09 & $75.19 \pm 0.85$ & 6.43 \\
\hline HG & $103.64 \pm 1.96$ & 7.32 & $81.86 \pm 1.66$ & 12.52 \\
\hline RW & $26.21 \pm 0.52$ & 1.93 & $19.04 \pm 0.36$ & 2.69 \\
\hline EL & $22.89 \pm 0.57$ & 2.13 & $21.21 \pm 0.31$ & 2.34 \\
\hline $\mathrm{CC}$ & $15.00 \pm 0.43$ & 1.62 & $10.72 \pm 0.14$ & 1.06 \\
\hline HW & $18.50 \pm 0.55$ & 2.07 & $14.37 \pm 0.15$ & 1.14 \\
\hline RH & $76.93 \pm 4.48$ & 4.48 & $61.81 \pm 0.67$ & 5.09 \\
\hline
\end{tabular}

BW: Body Weight, BL: Body Length, HG: Heart Girth, RW: Rump Width, EL: Ear Length, CC: Canon Circumference, HW: Head Width, RH: Rump Height

Table 2: Phenotypic correlation among traits male below diagonal and female above diagonal

\begin{tabular}{|c|c|c|c|c|c|c|c|c|}
\hline Traits & $\mathrm{BW}$ & $\mathrm{BL}$ & $\mathrm{HG}$ & RW & EL & $\mathrm{CC}$ & HW & $\mathrm{RH}$ \\
\hline$\overline{\mathrm{BW}}$ & & $0.727^{* * *}$ & $0.564^{* *}$ & $0.361^{* * *}$ & $0.340^{* * *}$ & $0.642^{* * *}$ & $0.223^{*}$ & $0.317^{*}$ \\
\hline BL & $0.621^{* *}$ & & $0.351^{* *}$ & $0.402^{* * *}$ & $0.513^{* *}$ & $0.603^{\text {*** }}$ & $-0.020^{\mathrm{ns}}$ & $-0.048^{\mathrm{ns}}$ \\
\hline $\mathrm{HG}$ & $0.828^{* *}$ & $0.617^{* *}$ & & $0.296^{*}$ & $0.332^{\text {** }}$ & $0.482^{* * *}$ & $0.177^{\mathrm{ns}}$ & $0.207^{\mathrm{ns}}$ \\
\hline RW & $0.311^{\mathrm{ns}}$ & $0.514^{*}$ & $0.485^{*}$ & & $0.369^{* *}$ & $0.509^{* * *}$ & $0.019^{\text {ns }}$ & $0.233^{*}$ \\
\hline EL & $-0.251^{\mathrm{ns}}$ & $0.174^{\mathrm{ns}}$ & $-0.158^{\mathrm{ns}}$ & $0.043^{\text {ns }}$ & & $0.469^{* * *}$ & $-0.177^{\mathrm{ns}}$ & $0.008^{\mathrm{ns}}$ \\
\hline $\mathrm{CC}$ & $0.358^{\mathrm{ns}}$ & $0.711^{* *}$ & $0.474^{*}$ & $0.444^{\mathrm{ns}}$ & $0.502^{*}$ & & $-0.177^{\mathrm{ns}}$ & $0.191^{\mathrm{ns}}$ \\
\hline HW & $0.512^{*}$ & $0.625^{* *}$ & $0.389^{\mathrm{ns}}$ & $0.473^{*}$ & $0.057^{\mathrm{ns}}$ & $0.276^{\mathrm{ns}}$ & & $0.292^{*}$ \\
\hline $\mathrm{RH}$ & $0.558^{*}$ & $0.518^{*}$ & $0.475^{*}$ & 0.394 & $0.084^{\mathrm{ns}}$ & $0.414^{\mathrm{ns}}$ & $0.611^{*}$ & \\
\hline
\end{tabular}

BW: Body Weight, BL: Body Length, HG: Heart Girth, RW: Rump Width, EL: Ear Length, CC: Canon Circumference, HW: Head Width, RH: Rump Height, ${ }^{* *}$ : Correlation significant at $\mathrm{P}<0.01,{ }^{*}$ : Correlation significant at $\mathrm{P}<0.05$, ns: Not significant 


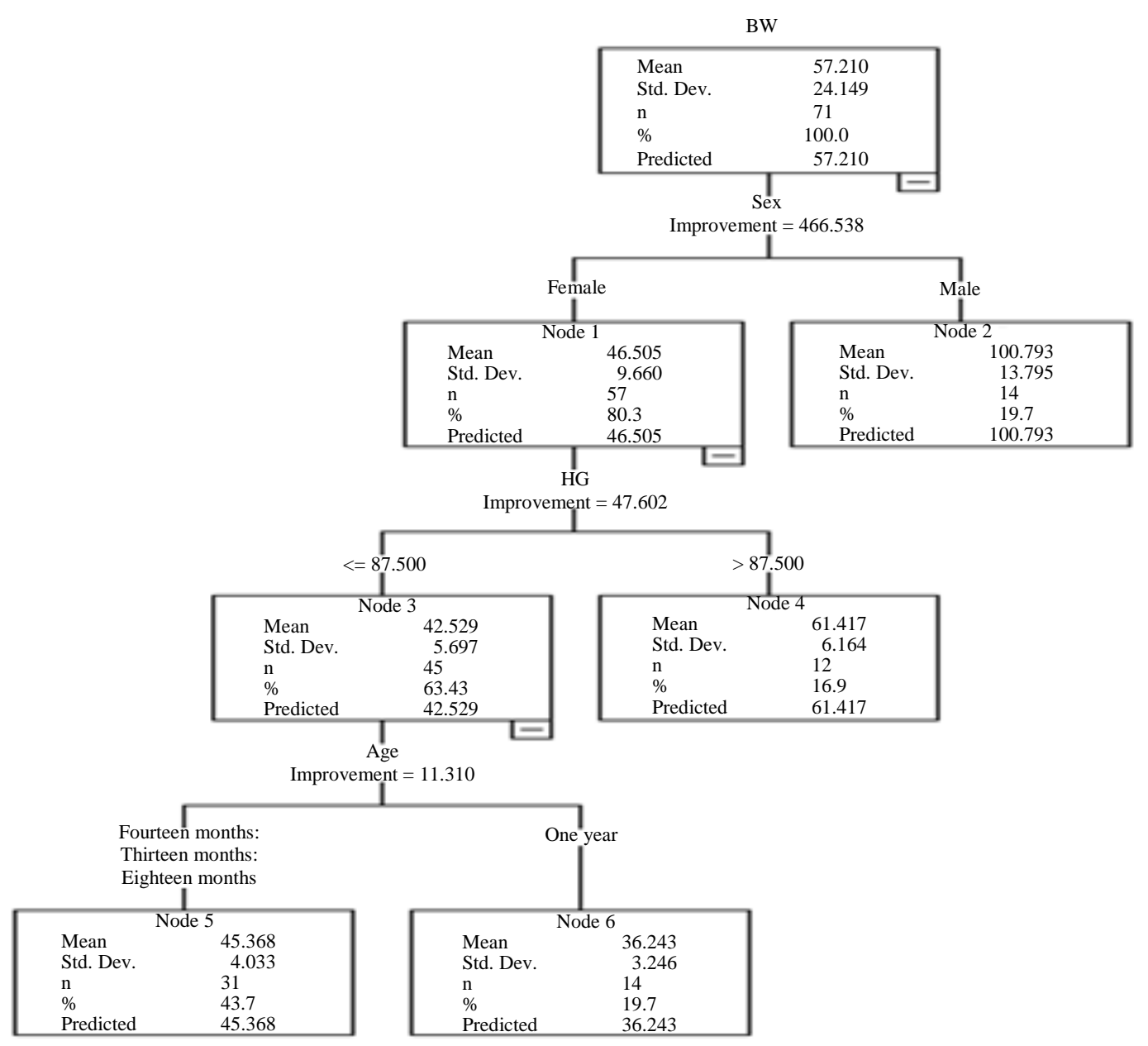

Fig. 2: Showing classification and regression tree model

\section{Discussion}

Morphometric traits can be used by resource-limited Boer goats' farmers as a selection criterion, for breeding and when practicing other animal management. This study investigate relation between body weight and morphometric traits viz. body length, cannon circumference, rump width, heart girth, rump height, ear length and head width of yearling Boer goats using Pearson correlation in both sexes. The results in Table 2 above diagonal showed that body weight had a highly positive significant correlation with body length, cannon circumference, heart girth, rump width and ear length and a positive significant correlation with rump height and head width in female (doe) yearling Boer goats, respectively. The findings advise that by improving body length, cannon circumference, heart girth, rump width, ear length, rump height and head width in female (doe) yearling Boer goats might also influence body weight positively. In male (buck) yearling Boer goats below the diagonal in Table 2, results revealed that body weight had no significant correlation with rump width, ear length and cannon circumference. These results means that by improving rump width, ear length and cannon circumference in male (buck) yearling Boer goats might not impact the body weight. In the same male (buck) yearling Boer goats' results, body weight was identified having a highly positive significant correlation with body length and heart girth and a positive significant correlation with head width and rump height. These results indicate that by improving body length, heart girth, head with and rump height might improve body weight. Furthermore, our study showed that body length and heart girth might be employed to improve body weight in both male and female yearling Boer goats. Similar results were reported by (Karna et al., 2020) in different goat breeds and (Jakaria et al., 2019) in bali cattle. Tyasi et al. (2017) stated that correlation results indicate only the association between traits without showing the cause effect relation between the traits. Hence, classification and regression tree analysis were employed to develop a model for estimation of body weight using morphometric traits and 
two factors (sex and age) which affects body weight of animals. Our results showed that sex, heart girth and age explained $92 \%$ of variation in body weight of yearling Boer goats. The model developed from this study indicated that sex play a significant role on body weight in both sexes. It was also found that heart girth and age also affect body weight in female goats whereas in males, it was only sex which play role on body weight. This study revealed that sex is the most explanatory variable with significant effect on body weight of yearling Boer goats. Our findings were supported by (Eyduran et al., 2017) who showed sex as an explanatory variable which played significant role on body weight in Indigenous Beetal Goat of Pakistan. Celik (2019) showed different results from current study which revealed body length as trait that had a significant effect on the body weight. This might be due to different breeds, as they used Pakistan goats.

\section{Conclusion}

Results of the current study indicated that there is a relationship between body weight and morphometric traits in both sex of yearling Boer goats. However, only body length and heart girth were highly positive significant correlated to body weight of female and male yearling Boer goats, respectively. Classification and regression tree findings suggests that sex, heart girth and age had a role on body weight of yearling Boer goats. However, sex is the one which play a significant effect on the body weight of yearling Boer goats. Our findings might help resource-limited farmers, researchers and the extension officers to take into consideration the relationship between body weight and morphometric traits in yearling Boer goats. It might also help them on which trait to focus when improving body weight of their goats and which explanatory variable to look when estimating body weight. More studies need to be conducted on developing a model to predict body weight of yearling Boer goats and investigating association between morphometric traits and body weight yearling Boer goats, using more sample size or different animal breed.

\section{Acknowledgment}

The authors would like to thank the Pieter Smith Boer goat farm workers for their support during data collection and financial contribution of University of Limpopo, Department of Agricultural Economics and Animal Production. We also thank a Boer goat stud, Mr Pieter Smith for allowing us to use his animals for data collection.

\section{Authors Contributions}

Thobela Louis Tyasi: Designed the study and revised the manuscript and approved the final version.
Madumetja Cyril Mathapo: Collected data and analyzed the data and drafted the manuscript.

\section{Ethics}

Authors of this study followed the ethical principles of the University of Limpopo Animal Research Ethics Committee (AREC).

\section{References}

Casey, N. H., \& Van Niekerk, W. A. (1988). The Boer goat. I. Origin, adaptability, performance testing, reproduction and milk production. Small Ruminant Research, 1(3), 291-302. https://doi.org/10.1016/0921-4488(88)90056-9

Celik, S. (2019). Comparing Predictive Performances of Tree Based Data Mining Algorithms and MARS Algorithm in the Prediction of Live Body Weight from Body Traits in Pakistan Goats. Pakistan Journal of Zoology, 51(4), 1447-1456. http://dx.doi.org/10.17582/journal.pjz/2019.51.4.144 7.1456

Eyduran, E., Zaborski D., Waheed A., Celik S., Karadas K., \& Grzesiak, W. (2017). Comparison of the Predictive Capabilities of Several Data Mining Algorithms and Multiple Linear Regression in the Prediction of Body Weight by Means of Body Measurements in the Indigenous Beetal Goat of Pakistan. Pakistan Journal of Zoology, 49(1), 257-265. http://dx.doi.org/10.17582/journal.pjz/2017.49.1.2 57.265

Huma, Z. E., \& Iqbal, F. (2019). Predicting the body weight of Balochi sheep using a machine learning approach. Turkish Journal of Veterinary and Animal Sciences, 43(4), 500-506. http://dx.doi.org/10.3906/vet-1812-23

Jakaria, J., Sutikno, Ulum, M. K., \& Priyanto, R. (2019). Live Body Weight Assessment Based on Body Measurements in Bali cattle (Bos javanicus) at Extensive Rearing System. Pakistan Journal of Life and Social Sciences, 17(1), 17-23. https://www.researchgate.net/publication/34417284 5_Live_Body_Weight_Assessment_Based_on_Bod y_Measurements_in_Bali_cattle_Bos_javanicus_at_ Extensive_Rearing_System

Karna, D. K., Acharya, A. P., Das, B. C., Nayak, G. D., \& Dibyadarshini, M. R. (2020). Morphometry of Ganjam goats of Odisha and age specific body weight prediction from linear body measurements. The Pharma Innovation Journal, 171-175. https://www.thepharmajournal.com/archives/2020 /vol9issue4S/PartD/S-9-4-48-605.pdf 
Lukuyu, M. N., Gibson, J. P., Savage, D. B., Duncan, A. J., Mujibi, F. D. N., \& Okeyo, A. M. (2016). Use of body linear measurements to estimate live weight of crossbred dairy cattle in smallholder farms in Kenya. Springerplus, 5, 63. https://doi.org/10.1186/s40064016-1698

Lu, C. D. (2002). Boer Goat Production: Progress and Perspective. Hilo, Hawai'i 96720, USA. https://citeseerx.ist.psu.edu/viewdoc/download?doi= 10.1.1.550.3269\&rep=rep1\&type $=$ pdf

Norris, D., Brown, D., Moela, A. K., Selolo, T. C., Mabelebele, M., Ngambi, J. W., \& Tyasi, T. L. (2015). Path coefficient and path analysis of body weight and biometric traits in indigenous goats. Indian Journal of Animal Research, 49(5), 573-578. http://dx.doi.org/10.18805/ijar.5564

Olatunji-Akioye, A. O., \& Adeyemo, O. K. (2009). Liveweight and Chest Girth Correlation in Commercial Sheep and Goat Herds in Southwestern Nigeria. International Journal of Morphology, 27(1), 49-55. http://dx.doi.org/10.4067/S071795022009000100009

Piwczyński, D. (2009). Using classification trees in statistical analysis of discrete sheep reproduction traits. Journal of Central European Agriculture, $10(3)$, 303-309.
Tariq, M. M., Eyduran, E., Bajwa, M. A., Waheed, A., Iqbal, F., \& Javed, Y. (2012). Prediction of body weight from testicular and morphological characteristics in indigenous Mengali sheep of Pakistan: using factor analysis scores in multiple linear regression analysis. International Journal of Agriculture and Biology., 14, 590-594. http://www.fspublishers.org/published_papers/5435 4_..pdf

Tyasi, T. L., Qin, N., Jing, Y., Mu, F., Zhu, H. Y., Liu, D., ... \& Xu, R. (2017). Assessment of relationship between body weight and body measurement traits of indigenous Chinese Dagu chickens using path analysis. Indian Journal of Animal Research, 51(3), 588-593. https://doi.org/10.18805/ijar.v0iOF.69901

Tyasi, T. L., Mathapo, M. C., Mokoena, K., Maluleke, D., Rashijane, L. T., Makgowo, K. M., ... \& Mathye, N. D. (2020). Assessment of relationship between body weight and morphological traits of South African non-descript indigenous goats. Journal of Animal Health and Production, 8(1), 32-39. http://dx.doi.org/10.14737/journal.jahp/2020/8.1.32.39

https://jcea.agr.hr/en/issues/article/773 